\title{
A Weighted Scoring Based Rating Scale to Identify the Severity Level of Mathematics Anxiety in Students
}

\author{
https://doi.org/10.3991/ijim.v15i08.18627 \\ Maruf Ahmed Tamal ( $\left.{ }^{\varpi}\right)$, Rabia Akter \\ Daffodil International University, Dhaka, Bangladesh \\ tamal15-5620@diu.edu.bd \\ Syed Akhter Hossain \\ University of Liberal Arts Bangladesh, Dhaka, Bangladesh \\ Karim Mohammed Rezaul \\ Wrexham Glyndwr University, Wales, United Kingdom
}

\begin{abstract}
Mathematics Anxiety (MA) is a pessimistic emotional attitude towards math that negatively affects mathematics learning. Due to its adverse impacts on students, assessing Mathematics Anxiety (MA) in early-stage has become a burning need over time. Generally, the existing measures of assessing MA adopt primitive questionnaires, and unweighted rating scale based approaches designed for students' particular age range. As a consequence, this type of scale is not sufficient enough to use widely. To bridge this gap, considering 839 students, the present study has proposed a Weighted Scoring Based Mathematics Anxiety Rating Scale (WSB-MARS). The reliability and validity of the WSB-MARS were ensured by high item-internal consistency, 1-week test-retest reliability, and the expert panel (validity). The study's overall findings suggest that WSB-MARS is a reliable, valid, generalized scale to assess the severity level of mathematics anxiety in students. Besides, the proposed scale could be implemented as a mobile application system that may help teachers/guardians recognize the effective intervention techniques for alleviating mathematics anxiety.
\end{abstract}

Keywords - Mathematics anxiety, mathematics anxiety rating scale, math learning, assessment

\section{Introduction}

Mathematics is an essential cognitive skill not only for academic success but also for effective day-to-day functioning. Math is fundamental to a child's development \& communication skills in later life. It stimulates the brain and improves analytical and problem-solving abilities. As a consequence, mathematics is considered to be the foundation of science and other academic areas. As well as math is a strong predictor for later academic success in school. Despite having significance, many students show a negative attitude towards math due to Mathematics Anxiety (MA). Mathematics 
anxiety is a particular form of anxiety disorder that causes reluctance in learning and practicing math. It is a feeling of discomfort, apprehension, or fear that interferes with math performance and achievement [1]. At present, many students worldwide are suffering from MA, which adversely impacts their academic excellence, employability, and career progression. Because of its pandemic nature in students, this issue has received increasing attention from scholars in recent years. Generally, students begin to face an MA at elementary school, which gradually increases to intermediate and tertiary levels. Previous findings revealed that individuals with math anxiety show more brain activation in brain regions involved with negative emotions and less brain activation in brain regions involved with mathematical thinking [2]. These negative emotions create significant fear among students, encouraging them to avoid mathematical activities [3] and math-related careers [4].

On the other hand, this math avoidance leads students to low academic performance [5] and achievements [6]. As a result, MA is considered a substantial barrier to mathematical learning and is thought to hinder students' engagement and proficiency in metacognitive processes [7]. So, academicians are trying to figure out appropriate ways to overcome MA so that students can engage in math, achieve a good learning experience, and pursue a future math-oriented career.

Generally, two types of approaches are followed to overcome MA: (i) preventative control and (ii) detective control. In preventive control, various cognitive tools [8], [9], [10], and effective learning approaches [11-15] are followed that help students to learn Math with fun and realistic experiences rather than only theoretical exercises. These approaches increase students' attention to math and reduce the likelihood of math anxiety. On the other hand, detective controls are designed to identify the intensity of Mathematics Anxiety, and based on the severity; an effective remedial process is provided to overcome it. Several studies were found where scholars proposed various scales to assess and measure the severity level of MA. Among them, 98-items based MARS [16] is considered a very trusted and widely accepted measure for diagnosing MA. The reliability of MARS was ensured by test-retest $(\alpha=0.85)$ and internal consistency reliability $(\alpha=0.97)$. However, the main drawback of the MARS is that it takes a long administrative time to complete.

Consequently, the study [17] proposed a shorter version of MARS with 30-items whose primary purpose was to reduce the administrative time by keeping the validity and reliability the same as the original 98-items MARS. Later, in [18], 9-items based Abbreviated Math Anxiety Scale (AMAS) was introduced, which claimed a more correct and parsimonious approach to assess MA. Because of its fewer items and higher reliability, AMAS has become popular to asses MA based on psychometric properties. At the same time, several translated [19-20], and researchers commonly use modified [21] versions of AMAS. As the majority of measures of MA are designed and implemented for adults and adolescents, in [23], researchers proposed a 19-items based Children's Mathematics Anxiety Scale UK (CMAS-UK), which was specially developed for children (Age range: 4-7) of the UK.

Although there are several scales outside, no significant structural changes have been observed. All these scales are mainly psychometric measurement of behavioral attitudes where students specify their degree (generally 1 to 5 , where one means less 
math-anxious and five means extremely math-anxious) of agreement or disagreement for a set of statements (items) and then sum up all the values where high scores indicate high Mathematics anxiousness. The key drawback of these existing scales is that the items (factors of MA) are considered equally important to assess MA. However, in reality, each item does not play an equal role in evaluating mathematics anxiety. To bridge this gap, the present study has proposed an effective detective control which identifies the severity level of Mathematics Anxiety of students more accurately. The purpose of the current study can be summarized as follows:

- Identifying the underlying factors of Mathematics Anxiety

- Categorizing the factors according to importance

- Introducing an effective mathematics anxiety rating scale called WSB-MARS

- Ensuring the reliability and validity of WSB-MARS

- Presenting a mobile application wireframe based on WSB-MARS

The rest of the study is arranged in the following way: in section 2, we discussed the methodological part. In section 3, we presented our proposed mathematics anxiety rating scale called WSB-MARS. In section 4, we explained the reliability and validity of WSB-MARS. In section 5, we have introduced a mobile application wireframe based on WSB-MARS. Lastly, in section 6, we discussed the overall study results and concluded with potential future work in this area.

\section{Research Methodology}

The methodology of the current study is split into several sub-sections for better understanding. In 2.1 , we briefly outlined the data collection procedures. In 2.2, we discussed how the data set was pre-processed to eliminate conflicting data, and finally, in 2.3, we showed the reliability of our survey instrument.

\subsection{Participants \& primary data collection procedures}

The present study has followed both qualitative and quantitative approaches to draw a meaningful research conclusion. At the initial stage, significant background work was conducted to identify the critical factors of mathematics anxiety. After finding out the responsible factors, all these factors were grouped into seven categories. Based on those findings, a survey (see Fig.1) was designed and distributed (between December 2019 and February 2020) to different class level students of 13 institutions (Level: primary, secondary \& tertiary) in Bangladesh. The survey has consisted of 16 self-constructed questionnaires (16-items) that describe internal, external, and cognitive symptoms related to students' mathematics anxiety (see Fig.1). Among 16 questionnaires/items, the first 15 items are based on a 4-point Likert scale, which is used to identify the severity level of mathematics anxiety of an individual student (Severity Range: 0 to 3), and the $16^{\text {th }}$ item represents whether a student is math-anxious or not (Range: 0 and 1). This $16^{\text {th }}$ item is included only for determining the importance of the other 15 items (see details in section 3). A total of 1500 sampled of survey were 
distributed online and offline, and 871 responses were gathered (Male $=557$ and Female $=314)$. The sample consisted of 147 primary level students $(16.89 \%), 331 \mathrm{sec}-$ ondary level students (38\%), and 393 tertiary level students $(45.12 \%)$. The age range of the participants was 7 to 25 .

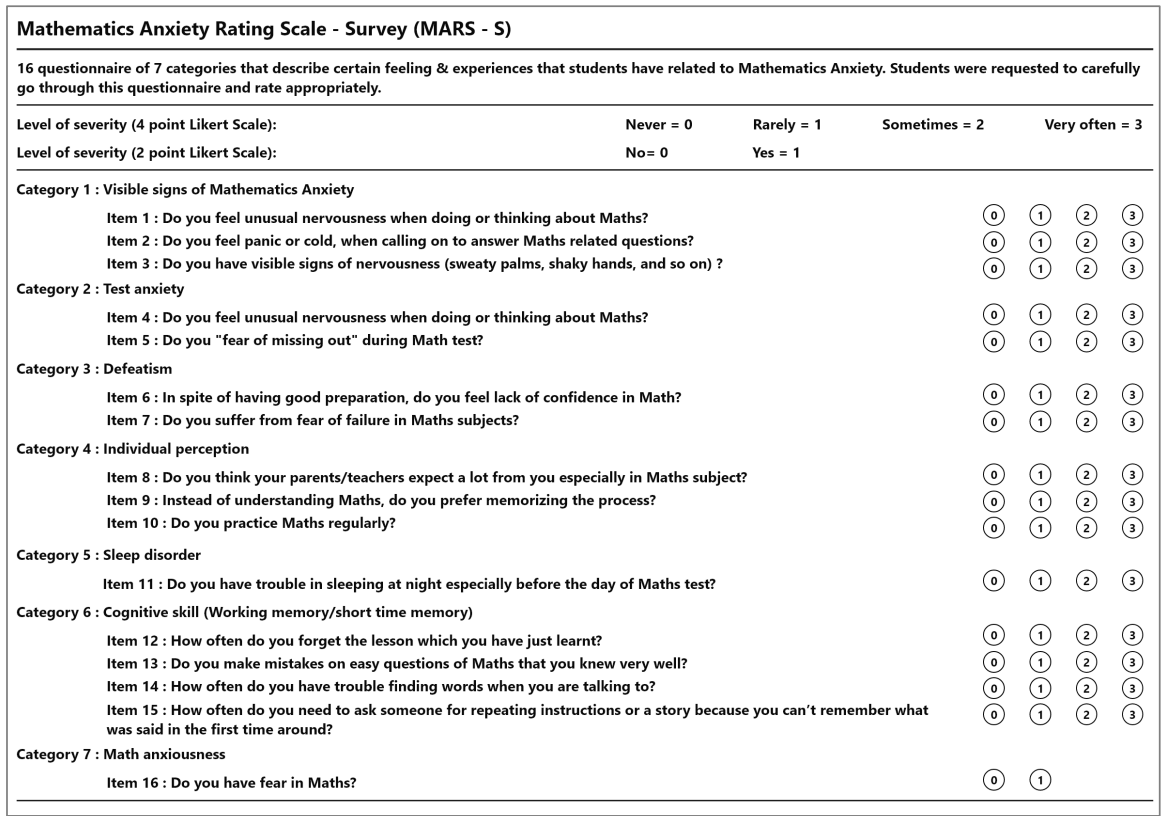

Fig. 1. Survey details

\subsection{Data pre-processing}

This primary data in this study was collected through both online and field surveys, which were then combined and used as an aggregate dataset. To get reliable and precise measurement, the aggregated dataset was fully preprocessed. We found $32 \mathrm{ab}-$ normal responses where seven records were irrelevant (i.e., responders added information that was not connected to the study), 16 records were incomplete (i.e., responders did not respond to all questionaries), and nine records were inconsistent and redundant (i.e., same responders responded both online and field survey with different answers). So, we have removed all those responses to get a more efficient result. After performing data pre-processing, 839 valid observations were selected for the next procedures.

\subsection{Reliability of the survey instrument (MARS-S)}

As illustrated above, the present study's observations were collected through a survey called MARS-S (see Fig.1), which consists of 16-items. It needs to be ensured that MARS-S can reliably fulfill the purpose of the study. Consequently, the reliabil- 
ity of the MARS-S was estimated by Cronbach's alpha $(\alpha)$ that measures the internal consistency of a group of items [see equation (i)].

$$
\alpha=\frac{N \bar{c}}{\bar{v}+(N-1) \bar{c}}
$$

Here, $\alpha=$ Cronbach's alpha, $N=$ number of items, $\bar{c}=$ average inter-item covariance, $\bar{v}=$ average variance.

Findings show that Cronbach's alpha of MARS-S is $\alpha=.93$, which indicates a high internal consistency of 16-items. The inter-item correlation matrix of MARS-S also shows positive scores, which indicates those 16-items are working as a group to fulfill the goal without any contrast (see Table 1.).

Table 1. Inter-item correlation matrix

\begin{tabular}{|c|c|c|c|c|c|c|c|c|c|c|c|c|c|c|c|c|}
\hline & I1 & I2 & I3 & I4 & I5 & I6 & I7 & I8 & I9 & I10 & I11 & I12 & I13 & I14 & I15 & I16 \\
\hline I1 & 1.00 & & & & & & & & & & & & & & & \\
\hline I2 & .577 & 1.00 & & & & & & & & & & & & & & \\
\hline I3 & .299 & .207 & 1.00 & & & & & & & & & & & & & \\
\hline I4 & .753 & .582 & .344 & 1.00 & & & & & & & & & & & & \\
\hline I5 & .497 & .437 & .257 & .478 & 1.00 & & & & & & & & & & & \\
\hline I6 & .636 & .532 & .367 & .681 & .511 & 1.00 & & & & & & & & & & \\
\hline I7 & .627 & .526 & .301 & .671 & .414 & .665 & 1.00 & & & & & & & & & \\
\hline I8 & .662 & .527 & .300 & .666 & .430 & .622 & .650 & 1.00 & & & & & & & & \\
\hline I9 & .424 & .354 & .223 & .483 & .374 & .469 & .409 & .421 & 1.00 & & & & & & & \\
\hline I10 & .480 & .531 & .164 & .419 & .388 & .416 & .447 & .472 & .282 & 1.00 & & & & & & \\
\hline I11 & .545 & .558 & .181 & .564 & .364 & .514 & .573 & .561 & .350 & .494 & 1.00 & & & & & \\
\hline I12 & .360 & .435 & .114 & .306 & .329 & .354 & .359 & .345 & .304 & .473 & .392 & 1.00 & & & & \\
\hline I13 & .582 & .493 & .227 & .577 & .532 & .588 & .560 & .518 & .421 & .461 & .525 & .439 & 1.00 & & & \\
\hline I14 & .454 & .474 & .204 & .461 & .433 & .468 & .482 & .451 & .404 & .452 & .450 & .541 & .576 & 1.00 & & \\
\hline I15 & .454 & .503 & .206 & .468 & .387 & .482 & .488 & .450 & .453 & .483 & .452 & .545 & .503 & .635 & 1.00 & \\
\hline I16 & .743 & .619 & .363 & .728 & .503 & .716 & .721 & .769 & .465 & .530 & .612 & .410 & .586 & .541 & .553 & 1.0 \\
\hline
\end{tabular}

\section{$3 \quad$ Research Results}

The core structure of WSB-MARS is illustrated in this section. In section 3.1, we demonstrated how to determine the items' weight based on their role in creating an MA. Lastly, in section 3.2, we discussed briefly how our proposed scale (WSBMARS) works.

\subsection{Determining the weight of the items based on importance}

In MARS-S (see Fig.1), the first 15 items are used to identify the severity level of mathematics anxiety, and the $16^{\text {th }}$ item represents whether a student is math-anxious or not. The primary purpose of the $16^{\text {th }}$ item is to help (as a target variable) identify the importance of the first 15 items in terms of diagnosing mathematics anxiety. In this current study, we used SelectKBest (Python Class) and a function called chi- 
squared to select items according to their highest scores. The column "Importance of Items (IOI)" of table 2 represents the scores of the first 15 items against the target variable (16th item). At the same time, the weighted point of the first 15 items (according to their degree) was calculated in column "Weighted Point (WP) = UP*IOI" (see Table 2).

Table 2. Scoring of items according to the importance

\begin{tabular}{|c|c|c|c|c|c|c|c|c|c|}
\hline I. No. & Importance & \multicolumn{3}{|c|}{ Unweighted Point (UP) } & \multicolumn{4}{|c|}{ Weighted Point (WP) = UP*IOI } \\
\cline { 3 - 10 } & $\begin{array}{c}\text { of Items } \\
(\text { IOI) }\end{array}$ & Never & Rarely & Sometimes & Very often & Never & Rarely & Sometimes & Very often \\
\hline 1 & 292.19 & 0 & 1 & 2 & 3 & 0 & 292.19 & 584.38 & 876.57 \\
\hline 2 & 333.21 & 0 & 1 & 2 & 3 & 0 & 333.21 & 666.42 & 999.63 \\
\hline 3 & 71.96 & 0 & 1 & 2 & 3 & 0 & 71.96 & 143.92 & 215.88 \\
\hline 4 & 308.57 & 0 & 1 & 2 & 3 & 0 & 308.57 & 617.14 & 925.71 \\
\hline 5 & 88.20 & 0 & 1 & 2 & 3 & 0 & 88.2 & 176.4 & 264.6 \\
\hline 6 & 313.22 & 0 & 1 & 2 & 3 & 0 & 313.22 & 626.44 & 939.66 \\
\hline 7 & 377.84 & 0 & 1 & 2 & 3 & 0 & 377.84 & 755.68 & 1133.52 \\
\hline 8 & 443.81 & 0 & 1 & 2 & 3 & 0 & 443.81 & 887.62 & 1331.43 \\
\hline 9 & 112.49 & 0 & 1 & 2 & 3 & 0 & 112.49 & 224.98 & 337.47 \\
\hline 10 & 187.16 & 0 & 1 & 2 & 3 & 0 & 187.16 & 374.32 & 561.48 \\
\hline 11 & 359.94 & 0 & 1 & 2 & 3 & 0 & 359.94 & 719.88 & 1079.82 \\
\hline 12 & 110.44 & 0 & 1 & 2 & 3 & 0 & 110.44 & 220.88 & 331.32 \\
\hline 13 & 145.89 & 0 & 1 & 2 & 3 & 0 & 145.89 & 291.78 & 437.67 \\
\hline 14 & 155.51 & 0 & 1 & 2 & 3 & 0 & 155.51 & 311.02 & 466.53 \\
\hline 15 & 193.17 & 0 & 1 & 2 & 3 & 0 & 193.17 & 386.34 & 579.51 \\
\hline
\end{tabular}

\subsection{Weighted scoring based rating scale}

After calculating the Weighted Point (WP) of each item (see Table 2), the cumulative value of all the WPs represents the severity score of the mathematical anxieties of a particular student. (See step 3, Algorithm 1). According to our proposed Weighted Scoring Based Mathematics Anxiety Rating Scale (WSB-MARS), the maximum or highest possible severity score can be 10480.8 , and the lowest or minimum possible severity score can be 0 . A higher severity score indicates higher mathematics anxiety, and a lower severity score indicates students' lower mathematics anxiety. For better understanding, the overall severity score has been divided into 4 stages e.g., NORMAL $(0<=$ severity_score $<=2,620)$, MILD $(2,620<$ severity_score $<=5,240)$, MODERATE $(5,240<$ severity_score $<=7,860)$ and SEVERE $(7,860<$ severity_score < 10481) (see step 4, Algorithm 1). 


\section{Algorithm 1. Weighted Scoring Based Rating Scale}

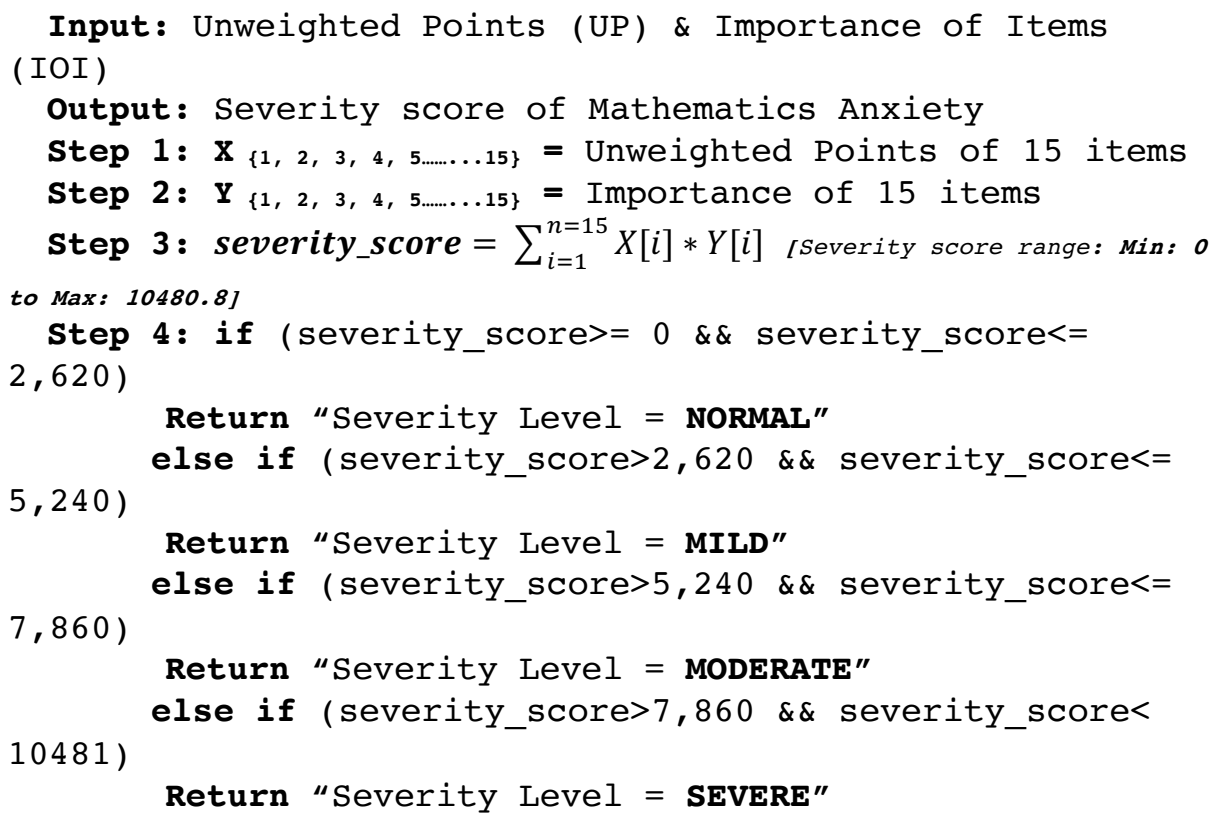

\section{Reliability and Validity of the Proposed Scale (WSB-MARS)}

\subsection{Reliability}

The reliability of our proposed scale WSB-MARS is ensured by the 1-week testretest reliability coefficient (see Fig.2). It's a measure of the reliability achieved by performing the same test twice in a group of people over a period of time [22]. About 150 students from different schools (primary, secondary, and tertiary) took part in the test twice a week. The mean of the first test result (severity score) was 4921.10 (SD = 2223.5) and the second test result was 4984.37 ( $\mathrm{SD}=2011.4)$. Pearson's correlation coefficient (see formula ii) between the two test scores was 0.968 . The overall finding confirms that WSB-MARS can reliably measure the Mathematics Anxiety of students.

$$
r=\frac{\sum\left(x_{i}-\bar{x}\right)\left(y_{i}-\bar{y}\right)}{\sqrt{\sum\left(x_{i}-\bar{x}\right)^{2} \sum\left(y_{i}-\bar{y}\right)^{2}}}
$$

Here, $\mathrm{r}=$ Pearson's correlation coefficient, $x_{i}=$ scores of the first test, $\bar{x}=$ mean of the first test scores, $y_{i}=$ scores of the second test, $\bar{y}=$ mean of the scores of the second test. 


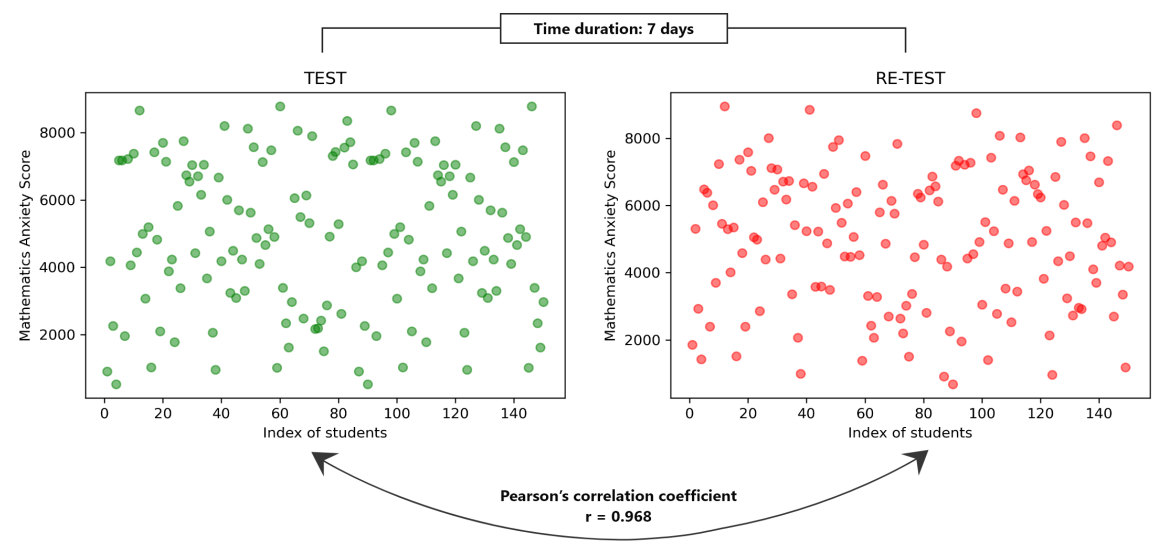

Fig. 2. Test-Retest reliability of WSB-MARS

\subsection{Validity}

The validity of the proposed scale (WSB-MARS) was ensured by the consultancy of the expert panel $(n=6)$ based on the following metrics: (i) Reliability of the survey instrument, (ii) Quality of the factors of mathematics anxiety, (iii) The ability of WSB-MARS to measure the severity level of mathematics anxiety (iv) Simplicity and (v) Administrative time to take a test. Table 3 provides the validity details of WSBMARS. Findings indicate that WSB-MARS is considered a valid instrument to assess MA.

Table 3. Validity test details

\begin{tabular}{|c|c|c|c|c|c|c|c|c|c|c|c|c|c|c|c|}
\hline \multirow{2}{*}{ Expert } & \multicolumn{3}{|c|}{ Metric (i) } & \multicolumn{3}{c|}{ Metric (ii) } & \multicolumn{3}{c|}{ Metric (iii) } & \multicolumn{3}{c|}{ Metric (iv) } & \multicolumn{3}{c|}{ Metric (v) } \\
\hline & Good & Ok & poor & Good & Ok & Poor & Good & Ok & Poor & Good & Ok & Poor & Good & Ok & Poor \\
\hline 1 & $\checkmark$ & & & & $\checkmark$ & & $\checkmark$ & & & $\checkmark$ & & & $\checkmark$ & & \\
\hline 2 & & $\checkmark$ & & $\checkmark$ & & & $\checkmark$ & & & & $\checkmark$ & & $\checkmark$ & & \\
\hline 3 & $\checkmark$ & & & $\checkmark$ & & & $\checkmark$ & & & & $\checkmark$ & & $\checkmark$ & & \\
\hline 4 & $\checkmark$ & & & $\checkmark$ & & & & $\checkmark$ & & $\checkmark$ & & & & $\checkmark$ & \\
\hline 5 & & $\checkmark$ & & $\checkmark$ & & & $\checkmark$ & & & $\checkmark$ & & & $\checkmark$ & & \\
\hline 6 & $\checkmark$ & & & & $\checkmark$ & & & $\checkmark$ & & & $\checkmark$ & & $\checkmark$ & & \\
\hline
\end{tabular}

\section{A Mobile Application Framework Based on WSB-MARS}

Generally, existing mathematics anxiety (MA) measures are used in education, research, psychology, clinical studies, etc., where researchers and academicians perform all the tasks manually rather than using an automated process. Consequently, it takes much time, effort, and money to complete the whole procedure. To overcome this gap, our proposed scale could be used as a mobile app to help teachers measure the severity level more quickly and take appropriate steps to reduce it. Fig. 3 represents the proposed mobile application wireframe, which highlights the functionalities and 
vital steps. Through this application, a teacher can efficiently perform several activities. Initially, a teacher needs to register himself/ herself with the necessary information to get into the apps. After successful registration, he/she will be able to log in and begin the next steps. After a successful login, he/she will be able to create a new test, set questions with additional information (options, default values, time limits, etc.), and assign the test to the target students. By default, there will be 15 questions from MARS-S. The teacher will determine the weight of each question, generate the rest report, and recommend an effective remedial program for a particular student. At the same time, a teacher will warn the students' guardians about their child's condition. On the other hand, students can also do different things, including selfregistration, performing the assigned test, taking notes, checking remedial programs via this application.

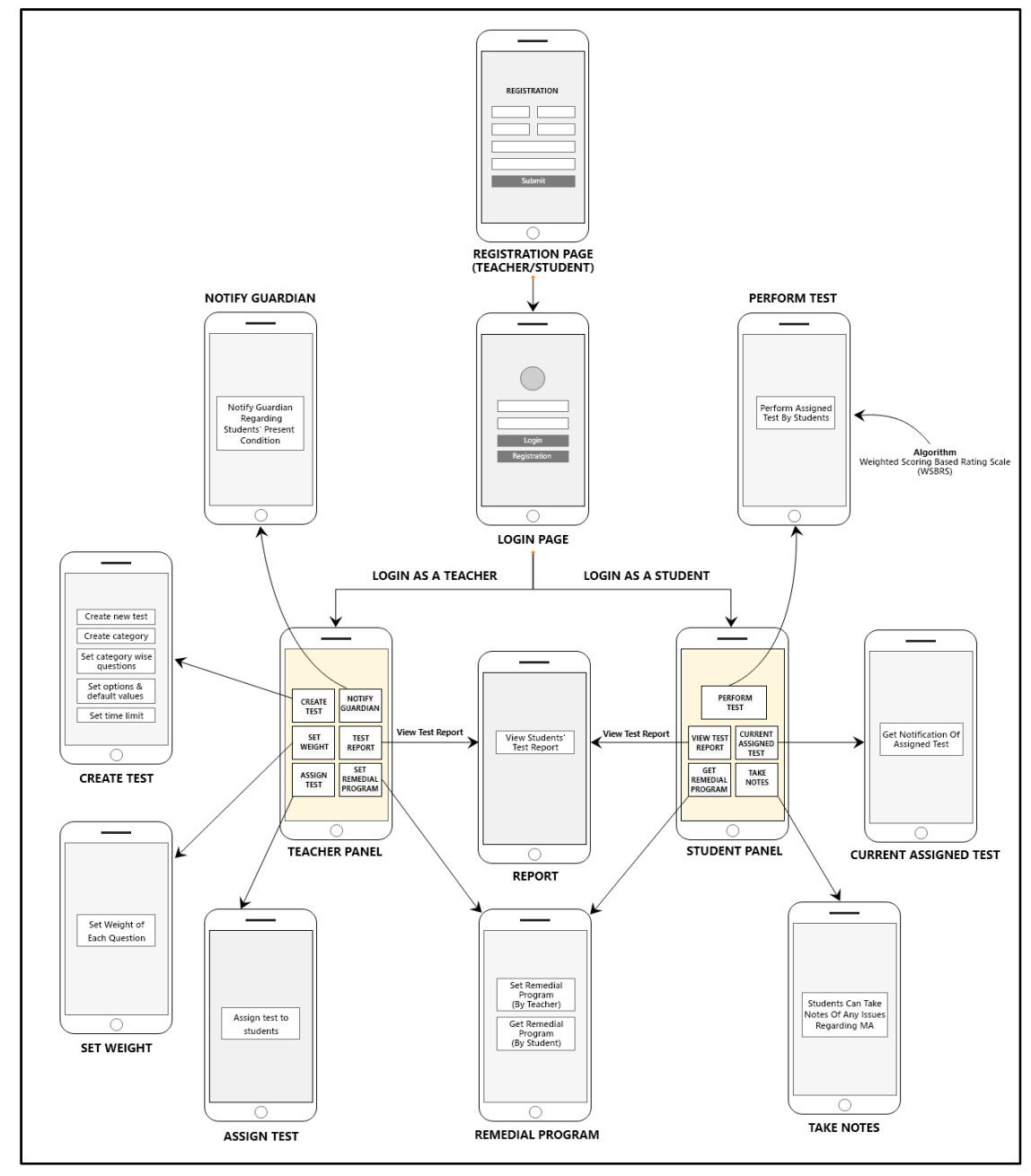

Fig. 3. Mobile application wireframe 


\section{Discussion and Conclusion}

Mathematics Anxiety (MA) has become a global concern nowadays. Early identification of the severity level of MA can reduce its negative impacts to a certain degree. Generally, two approaches are followed to alleviate Mathematics Anxiety: (i) preventative approach and (ii) detective approach. In this study, we introduced a detective instrument called Weighted Scoring Based Mathematics Anxiety Rating Scale (WSBMARS) that can assess the severity level of Mathematics Anxiety among students. The reliability and validity of the proposed WSB-MARS were ensured by iteminternal consistency (Cronbach's alpha: $\alpha=.93$ ), test-retest reliability: $r=.968$, and consultancy of an expert panel, respectively. Since WSB-MARS has 15 items, it takes a short administrative time to complete a test. This makes WSB-MARS easy to use compared to existing scales. Table 4 represents a comparative analysis between our proposed scale and the existing scales. Findings show that existing scales were designed for a particular age range of students. On the other hand, WSB-MARS is constructed based on primary, secondary \& tertiary level students.

Table 4. Comparative discussion

\begin{tabular}{|l|c|l|l|l|c|}
\hline \multicolumn{1}{|c|}{ Scale } & Total Items & $\begin{array}{c}\text { Targeted } \\
\text { Students/Age }\end{array}$ & Reliability Score & \multicolumn{1}{|c|}{$\begin{array}{c}\text { Sample Size } \\
\text { (N) }\end{array}$} & Ref. \\
\hline MARS & 98 & Tertiary Level & 0.85 (test-retest) & $\begin{array}{l}397(80 \% \text { Female, } \\
20 \% \text { Male })\end{array}$ & {$[12]$} \\
\hline $\begin{array}{l}\text { MARS } \\
\text { Short Version) }\end{array}$ & 30 & $\begin{array}{l}\text { Age range: } \\
17-26\end{array}$ & 0.90 (test -retest) & $\begin{array}{l}124(63 \text { Females, } 61 \\
\text { Males) }\end{array}$ & {$[13]$} \\
\hline AMAS & 9 & Ave. age: 19.6 & 0.85 (test-retest) & $\begin{array}{l}1,239(729 \text { Females, } \\
510 \text { Males) }\end{array}$ & {$[14]$} \\
\hline $\begin{array}{l}\text { AMAS } \\
\text { Italian Version) }\end{array}$ & 9 & Primary Level & 0.83 (test - retest) & $\begin{array}{l}1013(51 \% \text { Male, } \\
49 \% \text { Female })\end{array}$ & {$[15]$} \\
\hline AMAS-G & 9 & $\begin{array}{l}\text { Age range: } \\
18-35\end{array}$ & 0.82 (test -retest) $)$ & $\begin{array}{l}221(221 \text { Females, } 0 \\
\text { Male) }\end{array}$ & {$[16]$} \\
\hline mAMAS & 9 & $\begin{array}{l}\text { Age range: } \\
8-13\end{array}$ & 0.85 (test-retest) & $\begin{array}{l}1746(882 \text { Males, } \\
864 \text { Females) }\end{array}$ & {$[17]$} \\
\hline CMAS - UK & 19 & $\begin{array}{l}\text { Age range: } \\
4-7\end{array}$ & N/A & $\begin{array}{l}163(90 \text { Males, } 73 \\
\text { females) }\end{array}$ & {$[22]$} \\
\hline WSB -MARS & 15 & $\begin{array}{l}\text { Age range: } \\
7-25 \\
\text { primary, secondary } \\
\& \text { tertiary) }\end{array}$ & 0.968 (test - retest) & $\begin{array}{l}871(557 \text { Males, } \\
314 \text { Females). }\end{array}$ & $\begin{array}{l}\text { Our Proposed } \\
\text { Scale }\end{array}$ \\
\hline
\end{tabular}

The proposed scale (WSB-MARS) could be implemented as a mobile application that may help teachers/guardians find out the root of students' mathematics anxiety and its level of severity. As WSB-MARS is a reliable, valid, and new approach to assess the severity level of mathematics anxiety in students, it can be useful in the research and education field [24]. However, some limitations are still observed, like less primary data and preliminary validity tests. On the other hand, WSB-MARS is solely based on information from Bangladeshi students. As a consequence, effectiveness may vary outside Bangladesh. So, in the future, we expect to eliminate the above limitations and increase its effectiveness. 


\section{$7 \quad$ Acknowledgement}

The data collection process in this study was very challenging. However, the teachers' and students' cumulative effort from different level institutions in Bangladesh made this happen.

\section{References}

[1] M. A. Klados, E. Paraskevopoulos, N. Pandria, and P. D. Bamidis, "The Impact of Math Anxiety on Working Memory: A Cortical Activations and Cortical Functional Connectivity EEG Study," in IEEE Access, vol. 7, pp. 15027-15039, 2019, doi: 10.1109/ACCESS.2019.2892808. https://doi.org/10.1109/ACCESS.2019.2892808

[2] H. Sokolowski and D. Ansari, "Who Is Afraid of Math? What Is Math Anxiety? And What Can You Do About It?" Front. Young Minds, 2017 https://doi.org/10.3389 frym.2017.00057

[3] Kucian, Karin et al. "Relation Between Mathematical Performance, Math Anxiety, and Affec-tive Priming in Children with and Without Developmental Dyscalculia." Frontiers in psy-chology vol. 9 263. 26 April. 2018, https://doi.org/10.3389/fpsyg.2018.00263

[4] N. Suren, \& M. A. Kandemir, "The effects of mathematics anxiety and motivation on students' mathematics achievement." International Journal of Education in Mathematics, Science and Technology, vol. 8 No. 3, 190-218, 2020. https://doi.org/10.46328 /ijemst.v8i3.926

[5] J. Zhang, N. Zhao and Q. Kong, "The Relationship Between Math Anxiety and Math Performance: A Meta-Analytic Investigation," Frontiers in Psychology, vol. 10, 2019. Available: https://doi.org/10.3389/fpsyg.2019.01613

[6] Y. Mutlu, "Math Anxiety in Students With and Without Math Learning Difficulties," International Electronic Journal of Elementary Education, vol. 11, no. 5, pp. 471-475, 2019. https://doi.org/10.26822/iejee.2019553343

[7] F. Gabriel, S. Buckley and A. Barthakur, "The impact of mathematics anxiety on selfregulated learning and mathematical literacy," Australian Journal of Education, vol. 64, no. 3, pp. 227-242, 2020. https://doi.org/10.1177/0004944120947881

[8] M. Wangid, H. Rudyanto, and G. Gunartati, "The Use of AR-Assisted Storybook to Reduce Mathematical Anxiety on Elementary School Students," International Journal of Interactive Mobile Technologies (iJIM), vol. 14, no. 06, p. 195, 2020. https://doi.org/10.3991/ijim.v14i06.12285

[9] N. Ahmad and S. Junaini, "Augmented Reality for Learning Mathematics: A Systematic Lit-erature Review," International Journal of Emerging Technologies in Learning (iJET), vol. 15, no. 16, p. 106, 2020. https://doi.org/10.3991/ijet.v15i16.14961

[10] S. Papadakis, M. Kalogiannakis and N. Zaranis, "The effectiveness of computer and tablet assisted intervention in early childhood students' understanding of numbers. An empirical study conducted in Greece", Education and Information Technologies, vol. 23, pp. 18491871, 2018. https://doi.org/10.1007/s10639-018-9693-7

[11] J. Saha, S. Ahmmed, M. Ali, M. Tamal and K. Rezaul, "ICT Based Mathematics Skill Development Program: An Initiative to Overcome Mathematics Anxiety," International Journal of Emerging Technologies in Learning (iJET), vol. 15, no. 14, p. 252, 2020. https://doi.org/10.3991/ijet.v15i14.14149

[12] Papadakis, S., Kalogiannakis, M., and Zaranis, N. Improving Mathematics Teaching in Kin-dergarten with Realistic Mathematical Education. Early Childhood Education Journal, 45(3), pp.369-378, 2016. https://doi.org/10.1007/s10643-015-0768-4 
[13] Papadakis, S., Kalogiannakis, M., and Zaranis, N. Comparing Tablets and PCs in teaching Mathematics: An attempt to improve Mathematics Competence in Early Childhood Education. Preschool and Primary Education, 4(2), p.241.2016. https://doi.org/10.12681/ppej. $\underline{8779}$

[14] Papadakis, S., Kalogiannakis, M., and Zaranis, N., "The effectiveness of computer and tablet assisted intervention in early childhood students' understanding of numbers. An empirical study conducted in Greece", Education and Information Technologies, vol. 23, pp. 1849-1871, 2018. https://doi.org/10.1007/s10639-018-9693-7

[15] Dorouka, P., Papadakis, S., \& Kalogiannakis, M. (2020). Tablets and apps for promoting robotics, mathematics, STEM education and literacy in early childhood education. International Journal of Mobile Learning and Organisation, 14(2), 255-274, 2020. https://doi.org/ 10.1504/IJMLO.2020.106179

[16] F. Richardson and R. Suinn, "The Mathematics Anxiety Rating Scale: Psychometric data.", Journal of Counseling Psychology, vol. 19, no. 6, pp. 551-554, 1972. https://doi.org/ $10.1037 / \mathrm{h} 0033456$

[17] R. Suinn and E. Winston, "The Mathematics Anxiety Rating Scale, a Brief Version: Psychometric Data," Psychological Reports, vol. 92, no. 1, pp. 167-173, 2003. https://doi.org/ 10.2466/pr0.2003.92.1.167

[18] D. Hopko, R. Mahadevan, R. Bare, and M. Hunt, "The Abbreviated Math Anxiety Scale (AMAS)," Assessment, vol. 10, no. 2, pp. 178-182, 2003. https://doi.org/10.1177/1073191 $\underline{103010002008}$

[19] S. Caviola, C. Primi, F. Chiesi and I. Mammarella, "Psychometric properties of the Abbrevi-ated Math Anxiety Scale (AMAS) in Italian primary school children," Learning and Individ-ual Differences, vol. 55, pp. 174-182, 2017. https://doi.org/10.1016 ji.lindif.2017.03.006

[20] F. Schillinger, S. Vogel, J. Diedrich, and R. Grabner, "Math anxiety, intelligence, and performance in mathematics: Insights from the German adaptation of the Abbreviated Math Anxiety Scale (AMAS-G)," Learning and Individual Differences, vol. 61, pp. 109-119, 2018. https://doi.org/10.1016/j.lindif.2017.11.014

[21] E. Carey, F. Hill, A. Devine, and D. Szücs, "The Modified Abbreviated Math Anxiety Scale: A Valid and Reliable Instrument for Use with Children," Frontiers in Psychology, vol. 8, 2017. https://doi.org/10.3389/fpsyg.2017.00011

[22] Phelan, C., and Wren, J., n.d. Reliability and Validity. [online] Chfasoa.uni.edu. Available at: https://chfasoa.uni.edu/reliabilityandvalidity.htm [Accessed 26 October 2020].

[23] D. Petronzi, P. Staples, D. Sheffield, T. Hunt, and S. Fitton-Wilde, "Further development of the Children's Mathematics Anxiety Scale UK (CMAS-UK) for ages 4-7 years", Education-al Studies in Mathematics, vol. 100, no. 3, pp. 231-249, 2018. https://doi.org/10.1007/ s10649-018-9860-1

[24] Papadakis, St. Robots and Robotics Kits for Early Childhood and First School Age. Interna-tional Journal of Interactive Mobile Technologies (iJIM), 14 (18), 34-56, 2020. https://doi.org/10.3991/ijim.v14i18.16631

\section{Authors}

Maruf Ahmed Tamal is currently working as a lecturer \& Head of Quality assurance of NIET.UK. He also works as an associate researcher of the Bangladesh Digital Education Research Ltd., Gulshan 1, Dhaka, Bangladesh. He received his B.Sc. degree in Computer Science and Engineering from Daffodil International University, Dhaka, Bangladesh, in 2019. His primary area of expertise is machine learning and data mining-based knowledge discovery. He also pursues interests in ICT based Pedagogy. 
Rabia Akter is a researcher who received her B.Sc. degree in Computer Science and Engineering from Daffodil International University, Dhaka, Bangladesh, in 2019. His primary areas of expertise are Human-Computer Interaction (HCI), Data mining and the Internet of Things (IoT). He also pursues interests in the education field.

Professor Syed Akhter Hossain is currently the Head, Department of Computer Science and Engineering at University of Liberal Arts Bangladesh, one of the top leading digital university of Bangladesh from 1st January 2021. Prior to joining ULAB, Professor Hossain served as the Professor and Head of the Department of Computer Science and Engineering at Daffodil International University from 2010 to December, 2020. Professor Hossain obtained B.Sc. and M.Sc. in Applied Physics and Electronics with Gold medal and distinction and Ph.D. in Computer Science and Engineering with a post-doctoral research in automation and artificial intelligence. As Erasmus Mundus post-doctoral fellow he contributed in the area of Informatics and Industrial Engineering with University Lumiere Lyon 2 in France. He has more than 30 years of working experience in industry, education, research and training. He is actively involved in research guidance/ research projects/ research collaborations with Institutes/ Industries and has more than 250 publications/ presentations and his work is listed in ACM, DBLP, IEEE Explore and other research databases. He works closely with the ICT Division of the Ministry of Post, Telecommunication and IT of the Government of the Peoples Republic of Bangladesh. He received several national and international awards for his outstanding contribution in ICT education, innovative projects for the visually impaired people. He also received other International awards for his scholastic works specially for the contribution of machine translator for Bangla Braille used by the visually impaired society. He received best researcher award in the year 2019 from the university. His current research interests includes Machine Learning and AI with Natural Language Processing.

Karim Mohammed Rezaul was awarded a PhD degree in Computing and Communications Technology from North East Wales Institute (NEWI) of Higher Education (presently Wrexham Glyndŵr University), University of Wales, UK in October 2007. He received his BSc degree in the field of Naval Architecture and Marine Engineering from Bangladesh University of Engineering and Technology (BUET), Dhaka in 1998 and, MSc degree in Marine Technology from Norwegian University of Science and Technology (NTNU), Trondheim, Norway in 2001. Presently, he is a Professor of Computing \& Communications Technology at Wrexham Glyndwr University, UK and Adjunct Professor in Management at IPE Management School Paris, France. He is also a Professor of Computer Science \& Engineering (CSE) at Sonargaon University (SU), Dhaka, Bangladesh. Since 2002, Prof. Karim has been working as an Academic advisor and Programme director at various International colleges and universities in the UK and Bangladesh. Prof. Karim is an author of numerous Scientific and Business articles (Scholarly \& Refereed publications) which include book, book chapters, journals and International conference proceedings. He is an editor of several international journals and a member of the Technical Program Committee (TPC) of multiple International conferences. His research interests include IS Design and Development; ICT-based Pedagogy; Internet of Things (IoT); Artificial Intelligence (AI); Fractals and Nanotechnology; Networking - Traffic Engineering, Quality of Service (QoS) Control, Traffic modelling \&amp; simulation etc.; Distributed DBMS; Information Security; Business Intelligence; E-Business/E-commerce; ICT Project Management; Computing.

Article submitted 2020-09-16. Resubmitted 2021-01-08. Final acceptance 2021-01-08. Final version published as submitted by the authors. 